\title{
ABOVEGROUND BIOMASS ESTIMATES OF GRASSLAND IN THE NORTH TIBET USING MODIS REMOTE SENSING APPROACHES
}

\author{
CHU, D. \\ Tibet Institute of Plateau Atmospheric and Environmental Sciences, Tibet Meteorological \\ Bureau, Lhasa, China \\ Earth Science and Observation Center, Cooperative Institute for Research in Environmental \\ Sciences, University of Colorado, Boulder, USA
}

e-mail: chu_d22@hotmail.com; phone: +86-891-632-2873

(Received 26 $6^{\text {th }}$ May 2020; accepted $17^{\text {th }}$ Sep 2020)

\begin{abstract}
Grassland biomass is a key biophysical metrics to characterize grassland growth and a sensitive indicator of environmental change and ecological functioning. The quantification and timely information on aboveground biomass (AGB) of grassland are crucial for the sustainable use and management of grassland resources. In this study, AGB for main grassland types in the North Tibet was analyzed using field measurements and climatic controls of variations of aboveground biomass were explored, and the general estimate models for grassland AGB were further developed based on the relationships between MODIS vegetation indices (VIs) and the field measurements. The results indicated that alpine swamp meadow has the highest AGB of $356.8 \mathrm{~g} / \mathrm{m}^{2}$ on average, followed by temperate steppe $\left(64.5 \mathrm{~g} / \mathrm{m}^{2}\right)$ and alpine meadow $\left(61.6 \mathrm{~g} / \mathrm{m}^{2}\right)$, and AGB of alpine steppe is lowest at $48.9 \mathrm{~g} / \mathrm{m}^{2}$. Precipitation is main climate factor impacting variations of grassland AGB. The exponential relationships existed between grassland AGB and MODIS VIs and exponential models based on MODIS NDVI were found to be optimum for monitoring and estimating grassland AGB. Study also showed that AGB in the North Tibet spatially decreases from southeast to northwest, which is above $100 \mathrm{~g} / \mathrm{m}^{2}$ in the southeast and is below $20 \mathrm{~g} / \mathrm{m}^{2}$ in the northwest.
\end{abstract}

Keywords: aboveground biomass, alpine grasslands, estimate model, satellite remote sensing, Tibetan Plateau

\section{Introduction}

Grassland ecosystems are among the most important terrestrial ecosystems on the Earth, covering around one fourth of the Earth's terrestrial surface and providing essential ecosystem services, such as soil and water conservation, wind erosion prevention, sand fixation, wildlife habitat, air purification, and microclimate and global carbon cycle regulation (Dusseux et al., 2015; Han et al., 2018; Meng et al., 2018; Wang et al., 2019). Moreover, grassland ecosystems play a vital role in pasture animal husbandry development and environmental conservation, especially in areas where traditional animal husbandry practices (Zhang et al., 2018; Wang et al., 2019). Aboveground biomass (AGB) is an important component of grassland ecosystems and plays a critical role in the sustainable use of grassland resources and the global carbon cycle (Zhao et al., 2014; Eisfelder et al., 2017) and is a sensitive indicator of environmental change and ecological functioning, and largely influences biodiversity and environmental processes such as grassland degradation, hydrological cycle and soil erosion (Lu, 2006; Segoli et al., 2008; He et al., 2019). AGB also provides key information for understanding the responses of vegetation to climate change and resilience (Costanza et al., 1997; Houghton et al., 2000; Liang et al., 2016) and can be used to directly estimate grassland productivity (Lauenroth et al., 1986; Jobbagy et al., 2000; Meng et al., 2017). 
The quantification of AGB is particularly important to monitor areas under degradation and desertification (Eisfelder et al., 2017) and to identify regions that are more vulnerable to changing climate. Monitoring and estimating grassland AGB in degraded and desertified areas can not only show the vegetation growth condition but also provide evidence that ecosystem managers and scientists can evaluate the effects of ecological restoration in these areas to realize sustainable development of grassland ecosystems (Tsalyuk et al., 2015; Yan et al., 2015; Yang et al., 2018).

Satellite remote sensing with various temporal and spatial resolutions has been widely used to estimate grassland biomass at large scales while traditional biomass harvesting is a common and reliable method of estimating site-specific AGB and is the only way to provide indispensable ground truth for satellite remote sensing verification (Shen et al., 2008; Anaya et al., 2009; Jia et al., 2016). How to combine these two methods more effectively has become main approaches to more accurately estimating AGB at regional to global scales (John et al., 2018; Wang et al., 2018; Liu et al., 2018).

Tibet, referred to as Tibet Autonomous Region (TAR) here, is main body of the Tibetan Plateau (TP) and one of the five major livestock production zones and pastoral regions in China (Ministry of Agriculture of China, 1996; Chu et al., 2007; Bai et al., 2008). Grassland is the most extensive land cover type in Tibet and plays a vital role in animal husbandry development and environmental conservation. Due to geographical location, complex terrain, and various environmental and climatic conditions, grasslands in Tibet are diverse and are available from subtropical to alpine desert grassland types. Of 18 types of grasslands in China, 17 types can be found in Tibet with the exception of savanna (Tibet Land Management Bureau and Tibet Animal Husbandry Bureau, 1994).

Grasslands in Tibet have been experiencing degradation and desertification since the 1980s under impacts of climate warming, human activities, fast growing grazing pressure and rodent damage (Harris, 2010; Wang et al., 2013; Chen et al., 2014). Grassland degradation is one of the most widespread and severe environmental issues on the TP (Wang et al., 2007; Liu et al., 2015), especially in the arid and semi-arid areas in which vegetation is susceptible to climate variations. It has currently become social concerns and restriction factors for the sustainable development of animal husbandry and the environmental conservation in TAR (Liu et al., 1999; Gao et al., 2006).

Many scientists and research institutes have conducted various studies on grassland degradation and desertification as well as productivity change in Tibet area based on the vegetation indices obtained from different remote sensing satellite platforms to retrieve degree of grassland degradation and biomass change. The firs grassland resources survey in TAR was carried out in the 1980s (Tibet Land Management Bureau and Tibet Animal Husbandry Bureau, 1994). Liu et al. (2017) investigated the spatial and temporal patterns of grassland aboveground biomass on the Qinghai-Tibet Plateau based on the relationship between MODIS NDVI and field-sampled AGB. The estimate models for aboveground biomass of alpine desert grassland in the northern TP were developed based on the relationships between SPOT-VGT NDVI and field-sampled data (Liu et al., 2015). The spatial patterns and environmental controls of aboveground biomass in alpine grasslands on the TP were investigated by integrating field-collected AGB data and concurrent enhanced vegetation index derived from MODIS data sets (Yang et al., 2009). Liang et al. (2016) evaluated various methods for estimating the aboveground biomass of alpine grassland vegetation in pastoral area of southern Qinghai Province, in combination with long-term climate and grassland monitoring data, and developed an operational multi-factor model based on latitude, longitude, and grass cover. The 
artificial neural network and MODIS VIs were used to estimate grassland AGB in the Three-River Headwaters Region in the northeastern TP and it was found that the backpropagation artificial neural network model achieves better results than do the traditional multi-factor regression models (Yang et al., 2018).

Spatiotemporal dynamics of aboveground biomass (AGB) is a fundamental problem for the grassland management and environmental concerns on the TP. Advanced remote sensing is an effective approach for characterizing AGB, but the accuracy of the remote sensing-based inversion methods should be addressed and examined before putting into use. Compared to other pastoral regions in China, such as Inner Mongolia and Xinjiang provinces, few studies have focused on developing remote sensing-based approaches for estimating AGB in Tibet area and investigating climatic controls of AGB variations due to lack of continuous in-situ grassland observations. The spatial distribution and temporal variations of grassland biomass in Tibet also largely remain unknown. Particularly, there are no appropriate approaches available to more accurately estimating AGB of these inhomogeneous grasslands at larger spatial scales based on the remote sensing data, which can be used for monitoring grassland growth status and understanding degree of grassland degradation and desertification.

The study aims to present AGB magnitude of major grassland types in the North Tibet based on in-situ measurements first, and then to develop general models for AGB estimation using site-specific measurements and the corresponding MODIS vegetation indices, followed by analyzing main climatic controls of variations of AGB and validating models using independent ground truth data, and finally apply the proposed models to investigate the spatial distribution pattern of AGB in the study area. The study especially focuses on developing operational models suitable for monitoring grassland AGB for the TP area, which can be further used for understanding and providing timely information on grassland productivity, growth and degradation degree in the TP for the effective management and decision making to realize sustainable development of grassland resources.

\section{Materials and methods}

\section{Study area}

Study area is North Tibet, also named "Chang Tang" in Tibetan, which means Northern Plain, accounting for $42 \times 10^{4} \mathrm{~km}^{2}$ or $35 \%$ of total TAR area. Average elevation of study area is over 4500 meters above sea level (masl) and belongs to temperate alpine climate zone. Grassland is predominant land cover type in the North Tibet and plays a vital role in pasture animal husbandry development and environmental conservation (Zhang et al., 2013). Shrub and sub-alpine meadow are primary grassland type in southeastern region due to temperate monsoon humid climate condition. In central region, main grassland is alpine meadow with dominant species of kobresia pygmaea adapted to temperate monsoon semi-humid climate. The northwestern region is largely covered by alpine steppe with dominant species of stipa purpurea under temperate monsoon semi-arid climate condition. In the far northwest, alpine dessert is main grassland type due to temperate monsoon arid climate condition (Nakchu Bureau of Animal Husbandry, 1992; Chu et al., 2007). The southern region of study area consisted of Lhasa River basin and is mainly covered by temperate steppe and mountain steppe. In the North Tibet, annual precipitation generally increases from northwest to southeast, whereas temperature decreases from south to north. 


\section{Field measurements}

The in-situ measurements of AGB were carried out two times a month in 2004 to obtain accurate and site-specific grassland biomass and to provide ground truth for validation of satellite-based AGB estimation methods. Therefore, 10 sampling sites were set up in relatively homogenous and spatially representative region with typical grassland types. AGB samples in these sites were collected two times within 3 days every 15th and 30th day of the month during the vegetation growing season from June to September. In addition, AGB and vegetation coverage at Lhundup sampling site measured by the Tibet Institute of Animal Husbandry Sciences (TIAHS) in 2004 during the growing season within the study area were also used in the study and there were 11 observation sites in total (Table 1).

Table 1. AGB sampling sites and grassland/vegetation types

\begin{tabular}{|c|c|c|c|c|c|}
\hline Site & ongitude $/^{\circ}$ & Latitude $^{\mathbf{o}}$ & Altitude/m & Grassland type & Main vegetation type \\
\hline Damshung A & 91.1257 & 30.4975 & 4233 & Alpine swamp meadow & Kobresia littledalei \\
\hline Damshung B & .0959 & 30.4948 & 4249 & Alpine steppe & Stipa purpurea \\
\hline Damshung C & 90.9724 & 30.4127 & 4216 & Alpine meadow & $\begin{array}{c}\text { Kobresia pygmaea } \\
\text { Polygonum macrophyllum }\end{array}$ \\
\hline Damshung D & 90.6275 & 000 & 0 & Alpine & Kobresia pygmaea \\
\hline Damsl & 90.8933 & 30.3 & & Alpine swamp meadow & Kobresia pygmaea \\
\hline Yangbajian & 90.4720 & 30.0761 & 4300 & Alpine steppe & Stipa purpurea \\
\hline Riduo A & 92.2927 & 29.6908 & 4418 & Alpine meadow & Kobresia pygmaea \\
\hline Riduo B & 92.0968 & 29.7 & 4150 & Alpine swamp meadow & $\begin{array}{c}\text { Dasiphora parvifolia, } \\
\text { Kobresia pygmaea }\end{array}$ \\
\hline Lamu & 91.5444 & 29.8043 & 3720 & Temperate steppe & Artemisia younghusbandii \\
\hline Lhasa & 91.1452 & 29.6251 & 3693 & Temperate $\mathrm{s}$ & $\begin{array}{l}\text { Artemisia younghusbandii, } \\
\text { Pennisetum flaccidum }\end{array}$ \\
\hline Lhundup & 91.2363 & 30.0919 & 4546 & Alpine meadow & Kobresia pygmaea \\
\hline
\end{tabular}

In each sampling site, all aboveground biomass was clipped at ground surface in three quadrats of $0.5 \mathrm{~m} \times 0.5 \mathrm{~m}$, and all residual litter and other non-plant materials were removed by hand from the harvested samples. Vegetation coverage, dominant species and digital photographs for each quadrat and vegetation type, latitude, longitude and elevation for each site were also recorded. All AGB samples collected were separated into green and residual materials and were oven-dried at $85^{\circ} \mathrm{C}$ for 24 hours until a constant dry biomass was obtained at the grassland laboratory of TIAHS. The average AGB value of three quadrats within one site was used to represent the AGB at one site. Biomass is expressed in dry weight per unit area since fresh weight varies according to environmental conditions (Barrachina et al., 2015). Dry weight of green grass material is green dry matter (GDM) content, also named green AGB, while dry weight of residual material is residual dry matter (RDM) content. AGB or total AGB is sum of GDM and RDM.

\section{Methods and data}

Vegetation indices derived from satellite remote sensing can reflect the photosynthetic activity of surface vegetation and have become the most effective approaches to biomass estimation at large spatial scales (Gaitán et al., 2013; Jin et al., 
2014). A great number of vegetation indices have been proposed to characterize surface vegetation, biophysical process and terrestrial ecosystems (Gao et al., 2013b; Barrachina et al., 2015; Liang et al., 2016).

MODIS data are suitable for studying grassland vegetation at large scales due to their spatial and temporal advantages. MODIS vegetation indices(VIs) can better response vegetation growing status as compared to previous coarse spatial resolution satellites such as NOAA AVHRR and SPOT VEGETATION due to high signal-to-noise ratio, improved spectral signature and spatial characteristics, narrower bandwidth and frequent global earth imaging (Salomonson et al., 2004), and have been successfully used to characterize large-scale vegetation growth and dynamic change and have become the main remote sensing data source for monitoring grassland biomass and other biophysical parameters on the surface from regional to global scales.

Among various vegetation indices, NDVI (Normalized Difference Vegetation Index) and EVI (Enhanced Vegetation Index) are most frequently used for regression model development of biomass estimation. NDVI is designed to reflect vegetation activity by using information on chlorophyll radiation absorption in the red band and radiation scattering by mesophyll in the near-infrared band (Shen et al., 2014) and is expressed as follows:

$$
N D V I=(N I R-R) /(N I R+R)
$$

where "NIR" is the surface reflectance in the near-infrared wavelength (MODIS band 2), and " $R$ " is the surface reflectance in the red wavelength (MODIS band 1).

However, the study shows that NDVI has several limitations, including saturation phenomenon in a multilayer closed canopy and sensitivity to both atmospheric aerosols and soil background (Heute, 1988; North, 2002). To overcome these limitations, EVI was developed as a new MODIS product to reduce saturation at high vegetation coverage and minimize impacts of soil background and atmospheric noise (Huete et al., 1994). EVI is expressed as follows:

$$
E V I=G \times\left[\frac{(N I R-R)}{\left(N I R+C_{1} \times R-C_{2} \times B+L\right)}\right]
$$

where " $B$ " is the surface reflectance in the blue band (MODIS band 3 ); " $C_{1}$ " is atmosphere resistance red correction coefficient $\left(\mathrm{C}_{1}=6.0\right)$; " $\mathrm{C}_{2}$ " is atmosphere resistance blue correction coefficient $\left(\mathrm{C}_{2}=7.5\right)$; " $\mathrm{L}$ " is canopy background brightness correction factor $(\mathrm{L}=1.0)$; " $\mathrm{G}$ " is gain factor $(\mathrm{G}=2.5)$.

To establish AGB estimate models, two cloud-free Terra/MODIS scenes on September 13 and 27 in 2004 received at Lhasa MODIS receiving station of Tibet Institute of Plateau Atmospheric and Environmental Sciences (TIPAES) were used in the study and radiometric and atmospheric corrections for two images were made accordingly. NDVI and EVI then were calculated based on the surface reflectances in MODIS band 1, band 2 and band 3 using Eq.1 and Eq.2. In August, there were no cloud-free MODIS images available for the study area due to rainy season. Thus, MODIS product (MOD13Q1) downloaded from NASA's Land Processes Distributed Active Archive Center (LP DAAC) was used. MOD13Q1 is provided every 16 days at $250 \mathrm{~m}$ spatial resolution as a gridded level-3 product in the sinusoidal projection, 
including Terra/MODIS NDVI and EVI data, which are computed from atmospherically corrected bidirectional surface reflectances that have been masked for water, clouds, heavy aerosols, and cloud shadows.

The climate data included monthly precipitation and temperature obtained from Tibet Meteorological Information Center of Tibet Meteorological Bureau, which is consistent with field measurements. Based on the principle of meteorological station nearest to sampling sites, climate data from three meteorological stations are available for the study. For the sampling sites Riduo A and B the climate data from Medro Gongkar meteorological stations were used, for Damshung A, B, D and Yangbajian the data from Damshung meteorological station were used, and for sampling sites Lamuxiang and Lhasa the data from Lhasa meteorological station were used.

\section{Results and discussions}

\section{$A G B$ size of different grassland types}

Vegetation growing seasons in the North Tibet last three months or less in general due to alpine climate and short monsoonal system, with starting in early June and ending in late August to early September, and its length decreases from southeast to northwest. Grassland vegetation tends to be mature from late August to early September and its production is generally at the highest stage in a year. However, constrained by alpine climate, soil and water conditions in this elevated plateau, grassland AGB is low compared to plain areas at same latitudes on the Earth. Averaged AGB of all grassland types is $96.9 \mathrm{~g} / \mathrm{m}^{2}$, among which average GDM and RDM is 77.7 and $19.2 \mathrm{~g} / \mathrm{m}^{2}$, respectively, with GDM accounting for $80.2 \%$ of AGB. In August and September, AGB in some sampling sites had no residual material appeared and only consisted of green plants (Table 2).

Table 2. Field-sampled aboveground biomass of grassland $\left(\mathrm{g} / \mathrm{m}^{2}\right)$

\begin{tabular}{c|c|c|c|c}
\hline Grassland type & Items & Maximum & Minimum & Mean \\
\hline \multirow{3}{*}{ Alpine steppe } & GDM & 45.1 & 26.2 & 39.0 \\
& RDM & 24.9 & 0.0 & 9.9 \\
& AGB & 58.2 & 41.6 & 48.9 \\
\hline \multirow{3}{*}{ Alpine meadow } & GDM & 70.1 & 18.9 & 44.4 \\
& RDM & 39.6 & 0.0 & 17.2 \\
& AGB & 91.8 & 37.1 & 61.6 \\
\hline \multirow{3}{*}{ Temperate steppe } & GDM & 77.1 & 23.7 & 52.1 \\
& RDM & 26.0 & 0.0 & 12.4 \\
& AGB & 87.2 & 49.7 & 64.5 \\
\hline \multirow{3}{*}{ Alpine swamp meadow } & GDM & 541.2 & 190.1 & 303.3 \\
& RDM & 81.3 & 22.7 & 53.6 \\
& AGB & 589.1 & 212.7 & 356.8 \\
\hline \multirow{2}{*}{ Average } & GDM & 541.2 & 18.9 & 77.7 \\
& RDM & 81.3 & 0.0 & 19.2 \\
& AGB & 589.1 & 37.1 & 96.9 \\
\hline
\end{tabular}

There are great discrepancies in AGB size in different grassland types and sampling sites, ranging from 37.1 to $589.1 \mathrm{~g} / \mathrm{m}^{2}$, affected by grassland types, geographical locations, water and temperature conditions and so forth. Among these, AGB of alpine 
swamp meadow in Damshung A located in lowland wetland near the Damshung County town is highest with $589.1 \mathrm{~g} / \mathrm{m}^{2}$, followed by Riduo B ranging from 212.7 to $327.0 \mathrm{~g} / \mathrm{m}^{2}$ as alpine swamp meadow also. Sampled AGB in the rest of sampling sites is lower than $100 \mathrm{~g} / \mathrm{m}^{2}$, with a minimum of $37.1 \mathrm{~g} / \mathrm{m}^{2}$ occurred in Riduo A as typical alpine meadow grassland. On average, AGB of alpine swamp meadow is highest with reaching up to $356.8 \mathrm{~g} / \mathrm{m}^{2}$, followed by temperate steppe $\left(64.5 \mathrm{~g} / \mathrm{m}^{2}\right)$ and alpine meadow $\left(61.6 \mathrm{~g} / \mathrm{m}^{2}\right)$, whereas AGB of alpine steppe is lowest at $48.9 \mathrm{~g} / \mathrm{m}^{2}$.

Likewise, there are considerable differences in GDM in four main grassland types as well, with a maximum of $541.2 \mathrm{~g} / \mathrm{m}^{2}$, a minimum of $18.9 \mathrm{~g} / \mathrm{m}^{2}$ and an average of $77.7 \mathrm{~g} / \mathrm{m}^{2}$. On average, GDM of alpine steppe is lowest with $39.0 \mathrm{~g} / \mathrm{m}^{2}$, followed by alpine meadow $\left(44.4 \mathrm{~g} / \mathrm{m}^{2}\right)$ and temperate steppe $\left(52.1 \mathrm{~g} / \mathrm{m}^{2}\right)$, while alpine swamp meadow also has the highest GDM of $303.3 \mathrm{~g} / \mathrm{m}^{2}$. Over the period from August to September the sampled value of RDM ranges $0-81.34 \mathrm{~g} / \mathrm{m}^{2}$. Alpine swamp meadow has the highest RDM of $81.3 \mathrm{~g} / \mathrm{m}^{2}$ and its lowest RDM reaches $22.7 \mathrm{~g} / \mathrm{m}^{2}$, which means residual dry plants always existed during the sampling period for alpine swamp meadow. In other three grassland types, the minimum of RDM is 0 , which means there were no residual dry plants existed for some samples in August and September. Averaged RDM of alpine swamp meadow is highest at $53.6 \mathrm{~g} / \mathrm{m}^{2}$, followed by alpine meadow $(17.2$ $\left.\mathrm{g} / \mathrm{m}^{2}\right)$ and temperate steppe $\left(12.4 \mathrm{~g} / \mathrm{m}^{2}\right)$, while RDM is lowest in alpine steppe of 10.0 $\mathrm{g} / \mathrm{m}^{2}$. Averaged RDM of all grassland types is $19.2 \mathrm{~g} / \mathrm{m}^{2}$, accounting for $19.8 \%$ of total AGB.

The study on aboveground biomass in the North Tibet conducted by the TIAHS shows that AGB of alpine steppe and alpine meadow in August is 52.5 and $63.2 \mathrm{~g} / \mathrm{m}^{2}$, respectively (Ji et al., 2008). Yang et al. (2009) reported that average AGB of alpine meadow is $68.8 \mathrm{~g} / \mathrm{m}^{2}$ and average AGB of alpine steppe is $50.1 \mathrm{~g} / \mathrm{m}^{2}$ in the North Tibet (Gao et al., 2009). The first grassland resources survey in TAR conducted in the 1980s shows that general aboveground biomass of grasslands in Tibet ranges from 30 to $75 \mathrm{~g} / \mathrm{m}^{2}$ (Nakchu Bureau of Animal Husbandry, 1992). The field measurements in the TP during the growing season of 2013 shows that average AGB of alpine meadow was $70.7 \mathrm{~g} / \mathrm{m}^{2}$ and average AGB value of alpine steppe was $49.9 \mathrm{~g} / \mathrm{m}^{2}$ (Liu et al., 2017). Liang et al. (2016) reported that there were considerable spatial variations in the grassland AGB in the northeastern TP and average AGB in the peak period of grassland growth ranges from 32.9 to $365.3 \mathrm{~g} / \mathrm{m}^{2}$.

These results are consistent with main findings and grassland AGB magnitude in this study. The vegetation types, height, composition, and other properties are substantially different between grassland types, which could produce different AGB values even given the same grassland types (Gao et al., 2013b). Moreover, geographic location, topography, climate, soil, and grass types in the plateau also make great differences in grassland AGB size from region to region (Zheng et al., 2004; Chu, 2020).

\section{Relationships between AGB and climate variables}

The climate variables affect grassland vegetation growth, while hydrothermal condition among the variables is main factor influencing vegetation growth and biomass accumulation. In order to reveal the effects of climate variables on AGB in different grassland types and sample sites, the relationships between AGB and precipitation, temperature were explored using linear regression models. The models were developed using total aboveground biomass and fresh grass biomass (green AGB or GDM) as dependent variables and precipitation and temperature as independent variables, 
respectively. The result is shown in Table 3. It is clear that the linear correlations between aboveground biomass of grassland and precipitation are more prominent as a whole. Except for Lamuxiang and Lhasa sample sites due to higher spatial heterogeneity than other grassland types and sample site Damshung A as artificially fenced lowland alpine swamp meadow, there were significant correlations between AGB and precipitation $(P<0.01)$ in all sample sites, whereas relationships with temperature were not statistically significant.

Table 3. Linear correlations between aboveground biomass and climate variables

\begin{tabular}{c|c|c|c|c}
\hline \multirow{2}{*}{ Sample site } & \multicolumn{2}{|c|}{ AGB } & \multicolumn{2}{c}{ Green AGB(GDM) } \\
\cline { 2 - 5 } & Precipitation & Temperature & Precipitation & Temperature \\
\hline Damshung A & 0.34 & 0.15 & $0.85^{* *}$ & $0.71^{*}$ \\
Damshung B & $0.88^{* *}$ & 0.68 & $0.97^{* *}$ & $0.82^{*}$ \\
Damshung D & $0.85^{* *}$ & 0.64 & $0.97^{* *}$ & $0.82^{*}$ \\
Yangbajian & $0.75^{*}$ & 0.66 & $0.97 * *$ & $0.84^{* *}$ \\
Riduo A & $0.80^{*}$ & 0.43 & $0.97 * *$ & $0.72^{*}$ \\
Riduo B & $0.72^{*}$ & 0.59 & $0.94^{* *}$ & $0.86^{* *}$ \\
Lamuxiang & 0.37 & 0.00 & $0.97^{* *}$ & $0.77^{*}$ \\
Lhasa & 0.14 & 0.15 & $0.94^{* *}$ & $0.82^{*}$ \\
\hline
\end{tabular}

Note: * represents $P<0.01$; ** represents $P<0.001$

Green AGB is dry weight of fresh grass biomass as biomass accumulation part produced through vegetation photosynthesis during the vegetation growing season. For all sample sites, the linear correlations between green AGB and precipitation were higher than that between total AGB and precipitation. Likewise, the linear relationships between green AGB and temperature were also obviously higher than that between total AGB and temperature. It is evident that precipitation is main climatic factor affecting grassland aboveground biomass in the study area and plays more important role than temperature for vegetation growth as a whole in this alpine monsoon climate zone. The correlation analysis above also indicates that the impact of climate factors (precipitation, temperature) on green biomass is more profound compared with total AGB. Biomass accumulation during the vegetation growing season is integratedly affected by precipitation and temperature in terms of climate perspective whereas precipitation contributes more to intra-annual variations of AGB than temperature and is main driving force of alpine grassland in the study area. These findings are consistent with the previous studies. The relationships between biomass and climate factors have been a key issue regarding the response of the grassland ecosystem to climate change (Gao et al., 2013a). In the Eurasian steppe region, precipitation is a principal climate factor impacting grassland ecosystem processes (Hsu et al., 2012; Gao et al., 2013a). Other studies have shown that climate is an important factor affecting aboveground biomass of temperate steppe in China, North America and South America, and its variations is mainly constrained by precipitation (Piao et al., 2009; Ma et al., 2010; Ni, 2011). In northern China the precipitation is a primary determinant for grassland ecosystem productivity, biomass accumulation, and inter-annual pattern of the AGB (Gao et al., 2013a). In the Tibetan Plateau, precipitation may serve as the primary driver of the onset and peak dates of greenness of alpine grasslands and it is reasonable to expect that precipitation plays a more important role in alpine grasslands under the pressure of rapid warming in the plateau (Wang et al., 2015). 


\section{AGB estimate models}

The essence of remote sensing-based biomass estimate method is to build empirical regression models based on the relationships between field-measured biomass and vegetation index derived from remotely sensed data to estimate biomass for larger spatial scales (Barrachina et al., 2015; Liang et al., 2016; Yuan et al., 2016; Liu et al., 2017; Eisfelder et al., 2017; Chu, 2020). In the study, biomass data collected in August and September were used to develop general AGB estimate models, while remaining data sampled in June and July were employed for model verification. The regression models were established by using sampled grassland AGB as a dependent variable and MODIS NDVI and EVI as independent variables, respectively. A linear and four commonly used nonlinear regression models ( $\mathrm{S}$ model, logarithmic, power and exponential models) were tested and compared in order to select optimal AGB estimate models for monitoring grasslands in the North Tibet. The coefficient of determination $\left(\mathrm{R}^{2}\right)$ and F-test values are used to evaluate the performance of the regression models. Results show that the relationship between AGB and MODIS VIs can be best expressed by exponential models. Based on the higher $\mathrm{R}^{2}$ and $\mathrm{F}$-test values for regression modeling, NDVI-based exponential model estimates the best with the highest $\mathrm{R}^{2}$ $\left(\mathrm{R}^{2}=0.63\right)$ and F-test values $(\mathrm{F}=49.21)$, as shown in Table 4. It means that NDVI-based exponential model explains the largest proportion $(63 \%)$ of total variation in AGB. Other models based on the NDVI explain less than $53 \%$ of total variation in AGB. The fitting performance of EVI $\left(\mathrm{R}^{2}=0.50, \mathrm{~F}=28.87\right)$ is slightly lower than NDVI for estimating AGB, which presents that the saturation effect caused by high vegetation coverage and the soil background effect are very limited in the study area since moderate vegetation coverage is dominant in the northern TP. That is to say, EVI has no its advantage over the NDVI for the study area. Instead, the effectiveness of estimating AGB by NDVI is slightly better than that by EVI, showing that NDVI is more appropriate for monitoring and estimating grassland AGB in the North Tibet.

Table 4. Regression models of aboveground biomass of grassland for the North Tibet

\begin{tabular}{|c|c|c|c|c|}
\hline Model & Vegetation index & Regression model & $\mathbf{R}^{2}$ & $\mathbf{F}$ \\
\hline \multirow{2}{*}{$\begin{array}{l}\text { Linear regression } \\
\qquad \mathrm{Y}=\mathrm{b}_{0}+\mathrm{b}_{1} \mathrm{x}\end{array}$} & NDVI & $Y=500.013 x-107.258$ & 0.52 & $31.01 *$ \\
\hline & EVI & $Y=908.641 x-118.609$ & 0.45 & $23.77^{*}$ \\
\hline \multirow{2}{*}{$\begin{array}{c}\text { Logarithmic } \\
\mathrm{y}=\mathrm{b}_{0}+\mathrm{b}_{1} \operatorname{Ln}(\mathrm{x})\end{array}$} & NDVI & $Y=258.805+165.992 \operatorname{Ln}(x)$ & 0.36 & $16.09 * *$ \\
\hline & EVI & $Y=366.057+179.264 \operatorname{Ln}(x)$ & 0.32 & $13.78 * *$ \\
\hline \multirow{2}{*}{$\begin{array}{c}\mathrm{S} \text { model } \\
\mathrm{y}=\mathrm{e}^{(\mathrm{b} 0+\mathrm{b} 1 / \mathrm{x})}\end{array}$} & NDVI & $\mathrm{Y}=\mathrm{e}^{(4.998-0.254 / \mathrm{x})}$ & 0.26 & $10.19 * *$ \\
\hline & EVI & $\mathrm{Y}=\mathrm{e}^{(5.170-0.189 / \mathrm{x})}$ & 0.26 & $10.34 * *$ \\
\hline \multirow{2}{*}{$\begin{array}{c}\text { Exponential model } \\
y=\mathrm{b}_{0} \mathrm{e}^{\mathrm{blx}}\end{array}$} & NDVI & $Y=19.421 \mathrm{e}^{(3.178 \mathrm{x})}$ & 0.63 & $49.21 *$ \\
\hline & EVI & $Y=19.251 \mathrm{e}^{(5.507 \mathrm{x})}$ & 0.50 & $28.87 *$ \\
\hline \multirow{2}{*}{$\begin{array}{l}\text { Power model } \\
\mathrm{y}=\mathrm{b}_{0}(\mathrm{x})^{\mathrm{b} 1}\end{array}$} & NDVI & $Y=204.493 x^{1.083}$ & 0.46 & $24.54 *$ \\
\hline & EVI & $Y=382.679 x^{1.121}$ & 0.38 & $17.77 *$ \\
\hline
\end{tabular}

Note: * represents $P<0.001$; ** represents $P<0.01$; and *** represents $P<0.05$

By using MODIS NDVI and EVI as independent variables respectively and fieldsampled green AGB as a dependent variable, the estimate models for green AGB (GDM) were also developed. A linear and four nonlinear regression models above were tested and assessed for model development. Result shows that NDVI-based exponential model 
performs the best for green AGB estimation as well with the highest $\mathrm{R}^{2}$ and F-test values, as shown in Table 5, which means NDVI-based exponential model explains the highest proportion (69\%) of total variation in AGB among models tested. Additionally, NDVI-based model $\left(\mathrm{R}^{2}=0.69, \mathrm{~F}=65.82\right)$ is better than that EVI-based model $\left(\mathrm{R}^{2}=0.59\right.$ and $\mathrm{F}=41.95$ ). It is obvious that for monitoring and estimating green aboveground biomass of grassland in the North Tibet the fitting performance of NDVI is also better than EVI and it is an optimal vegetation index to estimate green biomass in the study area.

Table 5. Regression models of green AGB (GDM) for the North Tibet

\begin{tabular}{|c|c|c|c|c|}
\hline Model & Vegetation index & Regression model & $\mathbf{R}^{2}$ & $\mathbf{F}$ \\
\hline \multirow{2}{*}{$\begin{array}{l}\text { Linear regression } \\
\qquad \mathrm{Y}=\mathrm{b}_{0}+\mathrm{b}_{1} \mathrm{x}\end{array}$} & NDVI & $Y=443.940 x-103.588$ & 0.51 & $29.75 *$ \\
\hline & EVI & $Y=830.422 x-119.282$ & 0.47 & $25.48 *$ \\
\hline \multirow{2}{*}{$\begin{array}{c}\text { Logarithmic } \\
\mathrm{y}=\mathrm{b}_{0}+\mathrm{b}_{1} \operatorname{Ln}(\mathrm{x})\end{array}$} & NDVI & $\mathrm{Y}=225.320+151.371 \operatorname{Ln}(\mathrm{x})$ & 0.37 & $16.95 *$ \\
\hline & EVI & $Y=328.219+166.867 \operatorname{Ln}(x)$ & 0.35 & $15.41 * *$ \\
\hline \multirow{2}{*}{$\begin{array}{c}\mathrm{S} \text { model } \\
\mathrm{y}=\mathrm{e}^{(\mathrm{b} 0+\mathrm{b} 1 / \mathrm{x})}\end{array}$} & NDVI & $\mathrm{Y}=\mathrm{e}^{(5.050-0.376 / \mathrm{x})}$ & 0.43 & $21.74 *$ \\
\hline & EVI & $\mathrm{Y}=\mathrm{e}^{(5.306-0.280 / \mathrm{x})}$ & 0.43 & $22.11 *$ \\
\hline \multirow{2}{*}{$\begin{array}{c}\text { Exponential model } \\
y=b_{0} \mathrm{e}^{\mathrm{b} 1 \mathrm{x}}\end{array}$} & NDVI & $\mathrm{Y}=10.929 \mathrm{e}^{(3.850 \mathrm{x})}$ & 0.69 & $65.82 *$ \\
\hline & EVI & $\mathrm{Y}=10.208 \mathrm{e}^{(6.916 \mathrm{x})}$ & 0.59 & $41.95 *$ \\
\hline \multirow{2}{*}{$\begin{array}{l}\text { Power model } \\
\mathrm{y}=\mathrm{b}_{0}(\mathrm{x})^{\mathrm{b} 1}\end{array}$} & NDVI & $Y=211.741 x^{1.427}$ & 0.60 & $43.07 *$ \\
\hline & EVI & $Y=512.346 x^{1.516}$ & 0.52 & $31.62 *$ \\
\hline
\end{tabular}

Note: *: $P<0.001 ; * *: P<0.01$; and $* * *: P<0.05$

It can be seen from Tables 4-5 that the exponential relationship between green AGB and NDVI $\left(\mathrm{R}^{2}=0.69\right)$ is better than that between total AGB and NDVI $\left(\mathrm{R}^{2}=0.63\right)$, which is attributed to high sensitivity of vegetation index to green vegetation compared to total vegetation cover in the presence of senescent vegetation (Butterfield et al., 2009; Hagen et al., 2012). It is clear that either using MODIS NDVI or EVI the performance of estimate models for green AGB is always better than that for total AGB, indicating that MODIS vegetation index is more applicable for green biomass estimation, which reflects unique spectral signature and response of green vegetation detected by satellite sensors (Zheng et al., 2004; John et al., 2018). Vegetation index is based on differences in reflectances between visible and near-infrared bands of satellite sensors, which presents that strong photosynthesis of green vegetation makes it has low reflectance and strong absorption in the red visible band and higher reflectance and weaker absorption in the near-infrared band (John et al., 2018; Wang et al., 2018). The most obvious differences in spectral responses for senescent and green vegetation presents that senescent vegetation has higher reflectance both in the red and near-infrared bands but has no strong absorption and low reflectance in the visible band like green vegetation due to chlorophyll absorption through photosynthesis. Furthermore, the reflectance of green vegetation in the near-infrared band is obviously higher than the reflectance of senescent or residual vegetation. Low chlorophyll content of senescent vegetation reduces the red-to-near infrared spectral contrast (Butterfield et al., 2009; Tsalyuk et al., 2015) and finally affects fitting performance of vegetation index for estimating grassland biomass. 
AGB estimate models for alpine meadow grassland in eastern TP were established using field-measured AGB and different remotely-sensed NDVI data and it was found that in the four types of grassland AGB estimation models (linear, logarithmic, power and exponential) the exponential model performs the best (Meng et al., 2018). Liu et al. (2015) presented that the relationship between grassland biomass and NDVI in the TP can be quantified by an exponential model with an acceptable coefficient of determination $\left(\mathrm{R}^{2}=0.58\right)$. Liang et al. (2016) reported that among the 12 VIs tested the MODIS NDVI exhibits the highest correlation with grassland AGB in the peak of grassland biomass in southern Qinghai Province in the northeastern TP and the NDVI-based exponential inversion model performs the best and is capable of accounting for $58 \%$ of the changes in the grassland AGB. In the North Tibet, the relationship between grassland AGB and vegetation indices showed a non-linear trend and the exponential function resulted in the best option for use in describing that relationship and around $90 \%$ of the changes in AGB can be explained by the changes estimated with the vegetation indices ( $\mathrm{Ji}$ et al., 2008). In addition to relatively mature and widely used empirically-based grassland AGB retrieval methods based on the relationship between field AGB measurements and vegetation indices, He et al. (2019) proposed a novel physically-based grassland AGB retrieval method and AGB time series estimated by the method agreed reasonably well with the expected temporal dynamic trends of the grassland in Zoige Area in the eastern TP, and it has the potential for operational monitoring of grassland AGB at regional and even larger scales since its greatest advantage is fully physical nature and no field measurement is needed.

\section{Model validation}

To verify accuracy of biomass estimation models for the North Tibet, AGB estimated by NDVI-based exponential model is validated using field-sampled AGB during June and July of 2004. The result is shown in Figure 1 and indicates that the linear correlation coefficient between field-sampled and NDVI-estimated AGB is 0.84, with statistically significant at a significance level $(p<0.001)$. In addition, average AGB sampled and estimated is $62.9 \mathrm{~g} / \mathrm{m}^{2}$ and $70.1 \mathrm{~g} / \mathrm{m}^{2}$, respectively, which means averaged AGB estimated by the model is $7.2 \mathrm{~g} / \mathrm{m}^{2}$ higher than that sampled data. The overall trend as shown in Figure 1 is that when field-measured AGB is lower than $50 \mathrm{~g} / \mathrm{m}^{2}$, NDVI will generally overestimate the actual AGB, while if it is higher than $90 \mathrm{~g} / \mathrm{m}^{2}$, NDVI-predicted AGB tends to underestimate the actual AGB, namely, a general trend of overestimation at lower AGB level and underestimation at the higher AGB level for MODIS VIs-estimated AGB, which is mainly attributed to great regional differences in grassland biomass, high spatial heterogeneity of grassland types, various influence factors from climate, environment and topography in the study area as well as model algorithm limitations. However, the linear correlation coefficient is 0.84 with RMSE (root mean square error) of $29.1 \mathrm{~g} / \mathrm{m}^{2}$ and MAE (mean absolute error) of $22.9 \mathrm{~g} / \mathrm{m}^{2}$. According to these statistic measures, it is concluded that estimating aboveground biomass of grassland in the North Tibet using MODIS NDVI is effective and reliable.

\section{Spatial distribution of $A G B$}

By using NDVI-based exponential model the spatial distribution of grassland AGB in the North Tibet was made and the final map is shown in Figure 2. It is clear that AGB presents decrease from southeast to northwest, corresponding well to precipitation gradient to a large extent in this region. AGB is over $100 \mathrm{~g} / \mathrm{m}^{2}$ in the southeastern 
regions while it is below $20 \mathrm{~g} / \mathrm{m}^{2}$ in the northwestern corners. In the North Tibet, non-vegetation areas account for $4.24 \%$ of the total area, including lakes, perennial snow, glaciers, and alpine bare rock etc. Based on intervals of $10 \mathrm{~g} / \mathrm{m}^{2}$ apart, the areas where AGB ranges $30-40 \mathrm{~g} / \mathrm{m}^{2}$ cover the largest extent with $37.7 \%$ of the total area, mainly distributed in central North Tibet, followed by AGB between $20-30 \mathrm{~g} / \mathrm{m}^{2}$ with accounting for $27.9 \%$ of the entire areas and distributing in broad northern region close to Kunlun mountain range. The third is AGB of $40-50 \mathrm{~g} / \mathrm{m}^{2}$ with covering $9.1 \%$ of total area, and is distributed in the northern region of Nyainqentanglha Mountains. Other areas with $10 \mathrm{~g} / \mathrm{m}^{2}$ intervals cover less than $10 \%$. AGB in the southeastern river valleys is above $100 \mathrm{~g} / \mathrm{m}^{2}$ due to more abundant rainfall and ground water, with accounting for $5.5 \%$ of total area and reaching over $200 \mathrm{~g} / \mathrm{m}^{2}$ in some lowland wetlands.

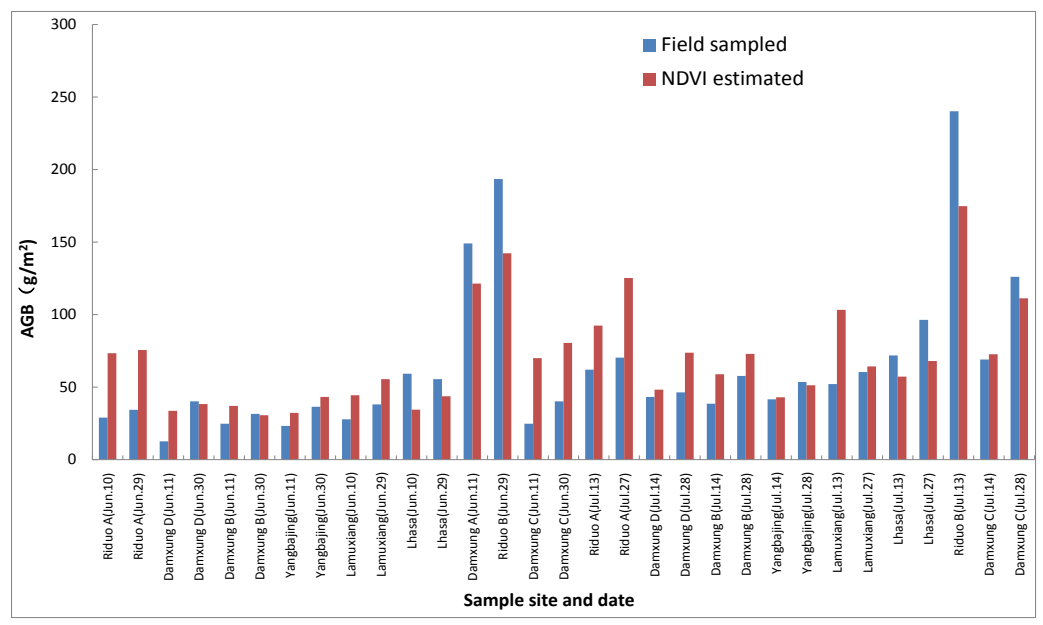

Figure 1. Comparisons between field-sampled and MODIS NDVI-estimated AGB

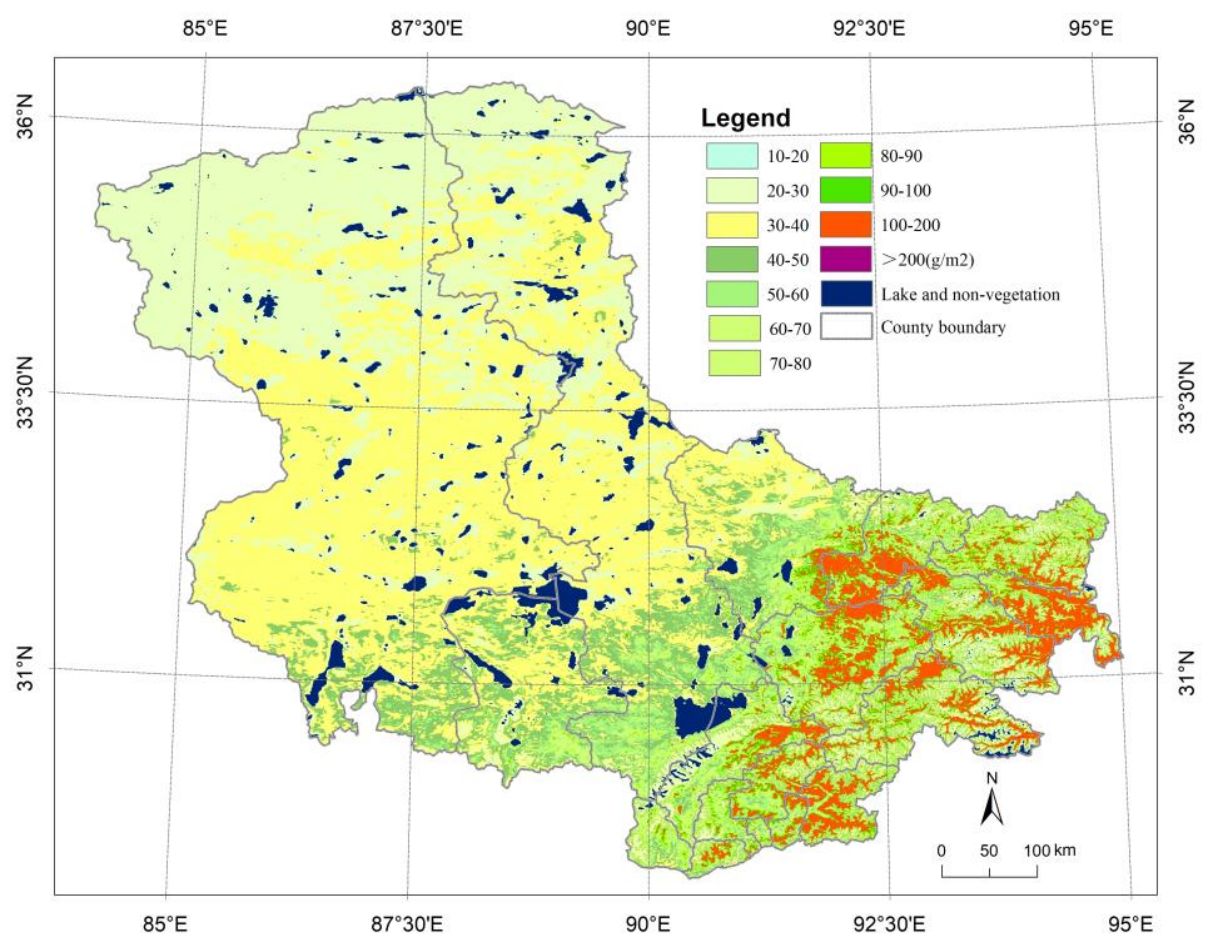

Figure 2. Spatial distribution of aboveground biomass of grassland in the North Tibet 
The spatial distribution of green AGB of grassland for the study area was also made using NDVI-based optimal model and the final result is shown in Figure 3. Its spatial distribution pattern is generally similar with total aboveground biomass, presenting gradually decrease from southeast to northwest. In the southeastern regions the green biomass is above $100 \mathrm{~g} / \mathrm{m}^{2}$ whereas it is lower than $20 \mathrm{~g} / \mathrm{m}^{2}$ in the northwestern regions. The green biomass ranges between 60 and $100 \mathrm{~g} / \mathrm{m}^{2}$ in most of southeastern regions while it ranges from 20 to $60 \mathrm{~g} / \mathrm{m}^{2}$ in central regions and is lower than $20 \mathrm{~g} / \mathrm{m}^{2}$ in the northwestern regions with covering $38.1 \%$ of total study area.

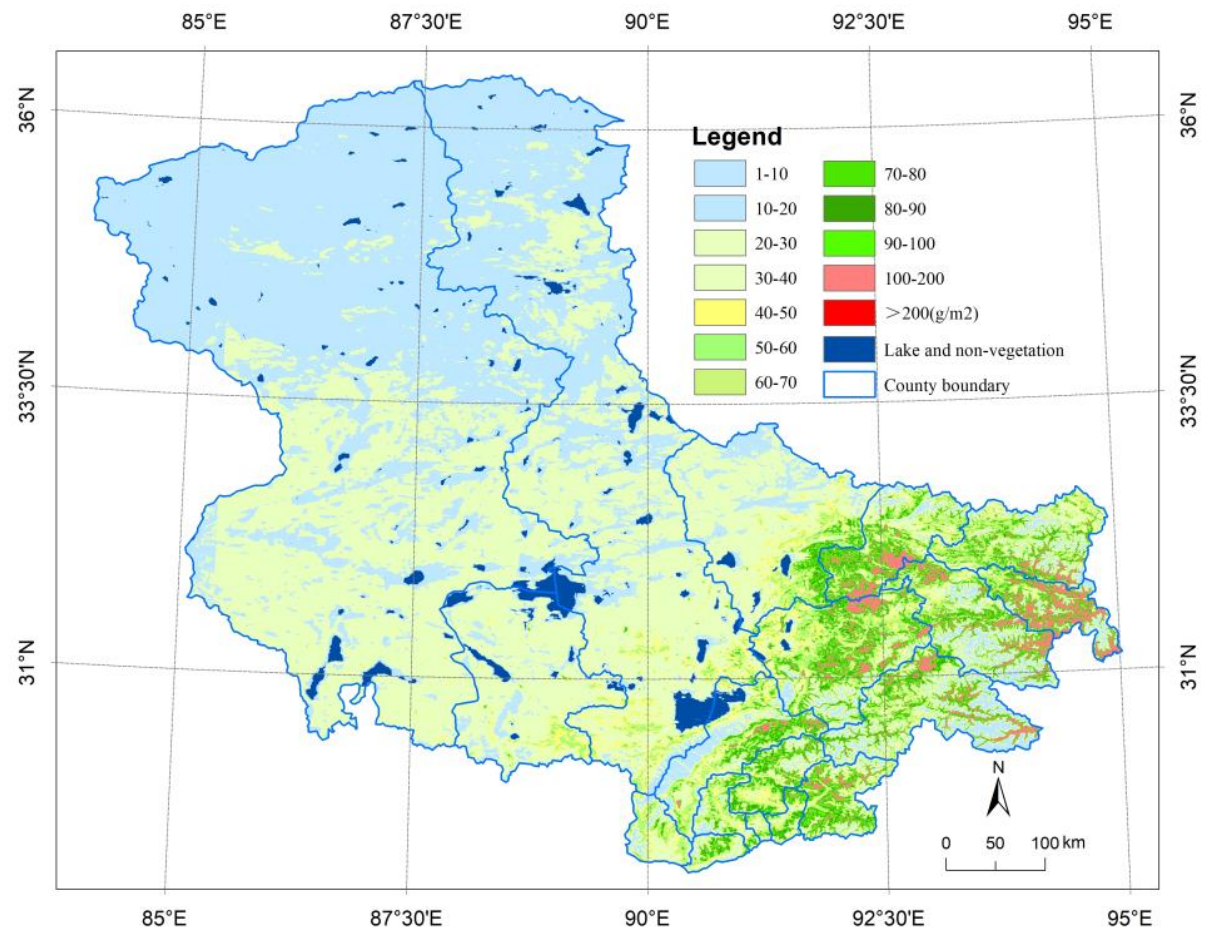

Figure 3. Spatial distribution of green AGB of grassland in the North Tibet

\section{Conclusions}

In this study, aboveground biomass of grassland for major grassland types in the North Tibet is investigated using field measurements of AGB first, and then empirical regression models for estimating grassland AGB are established based on the relationship between MODIS VIs and in-situ measurements and main climatic controls of AGB variations is further explored, and finally the spatial distribution of aboveground biomass in the North Tibet is mapped using optimum regression models developed. The study particularly focuses on combining field observations and remotely sensed data to develop methods for monitoring grassland biomass and generate a spatially explicit aboveground biomass map of grassland in the North Tibet.

(1) Affected by alpine climate, high attitude, soil fertility and moisture availability, grassland AGB in the North Tibet is low compared to same latitudes in the northern hemisphere. Average AGB of all grassland types between August and September is $96.9 \mathrm{~g} / \mathrm{m}^{2}$, of which green biomass is $77.7 \mathrm{~g} / \mathrm{m}^{2}$, accounting for $80.2 \%$ of the total AGB.

(2) AGB largely varies in different grassland types and sampling sites, ranging from 37.1 to $589.1 \mathrm{~g} / \mathrm{m}^{2}$. Based on the sample sites, AGB of alpine swamp meadow in 
Damshung A is highest at $589.1 \mathrm{~g} / \mathrm{m}^{2}$, while a minimum of $37.1 \mathrm{~g} / \mathrm{m}^{2}$ occurs in Riduo A. Based on the grassland types, average AGB of alpine swamp meadow is highest at $356.8 \mathrm{~g} / \mathrm{m}^{2}$, followed by temperate steppe $\left(64.5 \mathrm{~g} / \mathrm{m}^{2}\right)$ and alpine meadow $\left(61.6 \mathrm{~g} / \mathrm{m}^{2}\right)$, whereas AGB of alpine steppe is least at $48.9 \mathrm{~g} / \mathrm{m}^{2}$. Biomass accumulation during the vegetation growing season is jointly affected by precipitation and temperature and in contrast the precipitation plays more important role than temperature and is main driving force for vegetation growth in this alpine region.

(3) Vegetation index derived from remotely sensed data is an important indicator to represent the vegetation characteristics of land surface and has been widely used for grassland biomass estimates. The study found that optimum regression models for estimating aboveground biomass in the North Tibet are MODIS NDVI-based exponential models. The spatial distribution maps of aboveground biomass of grassland made using optimum models show that both AGB and green AGB presents decrease from southeast to northwest, which is above $100 \mathrm{~g} / \mathrm{m}^{2}$ in the southeastern regions and decrease lower than $20 \mathrm{~g} / \mathrm{m}^{2}$ in the northwestern margin.

(4) Due to limited physical access to the TP and large spatial extent, remote sensing observations are becoming main data source and realistic approaches in monitoring this unique environment and have great potentials to further apply in various biophysical parameters retrieval. However, current accuracy of AGB estimates based on vegetation indices is still limited due to lack of sufficient field-sampled data and spatial heterogeneity and complexity of grassland types. Given that the accuracy of remote sensing-based AGB estimate models is largely dependent on the number and representativeness of the sampling sites. Therefore, the collection of a sufficient number of biomass sample sites in representative regions is a key for developing robust AGB estimate models and evaluating the estimate results in the future.

(5) Timely monitoring and estimating aboveground biomass are important for ensuring sustainable grassland ecosystem function and maintaining its environmental conservation values. Satellite remote sensing provides only feasible approach to monitoring and estimating aboveground biomass at large spatial scales. However, grassland AGB estimate models based on a single factor such as vegetation index have limited accuracy and high uncertainty, which would be further improved using unmanned aerial vehicle technology and finer spatial-resolution remote sensing data in the future.

Acknowledgments. The author would like to thank Prof. Kristy Tiampo and Prof. Richard Armstrong for their assistance during my visiting University of Colorado at Boulder. MODIS product (MOD13Q1) was downloaded from NASA's Land Processes Distributed Active Archive Center (LP DAAC). The climate data was provided by the Meteorological Information and Network Center of Tibet Meteorological Bureau. This research work was financially supported by the Second Tibetan Plateau Scientific Expedition and Research Program (2019QZKK010312), the Science \& Technology Basic Resources Investigation Program of China (2017FY100501), the National Natural Science Foundation of China (41561017), and the Tibet Key Laboratory of Plateau Atmosphere and Environment Research through the Project of Scientific Investigation and Research for Main Land Surface Features in Tibet.

\section{REFERENCES}

[1] Anaya, J. A., Chuvieco, E., Palacios-Orueta, A. (2009): Aboveground biomass assessment in Colombia: A remote sensing approach. - Forest Ecology and Management 257: $1237-1246$. 
[2] Bai, Y. F., Wu, J. G., Xing, Q., Pan, Q. M., Huang, J. H., Yang, D. L., Han, X. G. (2008): Primary production and rain use efficiency across a precipitation gradient on the Mongolia Plateau. - Ecology 89: 2140-2153.

[3] Barrachina, M., Cristobal, J., Tulla, A. F. (2015): Estimating aboveground biomass on mountain meadows and pastures through remote sensing. - International Journal of Applied Earth Observation and Geoinformation 38: 184-192.

[4] Butterfield, H. S., Malmstrom, C. M. (2009): The effects of phenology on indirect measures of aboveground biomass in annual grasses. - International Journal of Remote Sensing 30: 3133-3146.

[5] Chen, B., Zhang, X., Tao, J., Wu, J., Wang, J., Shi, P., Zhang, Y., Yu, C. (2014): The impact of climate change and anthropogenic activities on alpine grassland over the Qinghai-Tibet Plateau. - Agricultural and Forest Meteorology 189: 11-18.

[6] Chu, D., Deji, Y., Pubu, C. (2007): The response of typical vegetation growth to climate conditions in the northern Tibetan Plateau. - Journal of Applied Meteorological Science 18(6): 832-839.

[7] Chu, D., Lu, L., Zhang, T. (2007): Sensitivity of Normalized Difference Vegetation Index (NDVI) to seasonal and inter-annual climate conditions in the Lhasa area, Tibetan Plateau, China. - Arctic, Antarctic, and Alpine Research 39(4): 635-641.

[8] Chu, D. (2020): Remote Sensing of Land Use and Land Cover in Mountain Region. Springer, Singapore.

[9] Costanza, R., d'Arge, R., de Groot, R., Farber, S., Grasso, M., Hannon, B., Limburg, K., Naeem, S., O’Neill, R. V., Paruelo, J., Raskin, R. G., Sutton, P., van den Belt, M. (1997): The value of the world's ecosystem services and natural capital. - Nature 387: 253-260.

[10] Dusseux, P., Hubert-Moy, L., Corpetti, T., Vertès, F. (2015): Evaluation of SPOT imagery for the estimation of grassland biomass. - International Journal of Applied Earth Observation and Geoinformation 38: 72-77.

[11] Eisfelder, C., Klein, I., Bekkuliyeva, A., Kuenzer, C., Buchroithner, M. F., Dech, S. (2017): Aboveground biomass estimation based on NPP time-series -A novel approach for biomass estimation in semi-arid Kazakhstan. - Ecological Indicators 72: 13-22.

[12] Gaitán, J. J., Bran, D., Oliva, G., Ciari, G., Nakamatsu, V., Salomone, J., Ferrante, D., Buono, G., Massara, V., Humano, G., Celdrán, D., Opazo, W., Maestre, F. T. (2013): Evaluating the performance of multiple remote sensing indices to predict the spatial variability of ecosystem structure and functioning in Patagonian steppes. - Ecological indicators 34: 181-191.

[13] Gao, Q., Li, Y., Lin, E., Jiangcun, W. (2006): Temporal and spatial distribution of grassland degradation in Northern Tibet. - Acta Geographica Sinica 60(6): 965-973.

[14] Gao, Q., Li, Y., Wan, Y., Qin, X., Jiangcun, W., Liu, Y. (2009): Dynamics of alpine grassland NPP and its response to climate change in Northern Tibet. - Climatic Change 97: 515-528.

[15] Gao, T., Yang, X., Jin, Y., Ma, H., Li, J., Yu, H., Yu, Q., Zheng, X., Xu, B. (2013a): Spatio-temporal variation in vegetation biomass and its relationships with climate factors in the Xilingol grasslands, northern China. - Plos One 8(12): e83824.

[16] Gao, Y., Liu, X., Min, C., He, H., Yu, G., Liu, M., Zhu, X., Wang, Q. (2013b): Estimation of the north-south transect of eastern China forest biomass using remote sensing and forest inventory data. - International Journal of Remote Sensing 34: 55985610.

[17] Hagen, S. C., Heilman, P., Marsett, R., Torbick, N., Salas, W., van Ravensway, J., Qi, J. (2012): Mapping total vegetation cover across western rangelands with ModerateResolution Imaging Spectroradiometer data. - Rangeland Ecology and Management 65: 456-467.

[18] Han, Z., Song, W., Deng, X., Xu, X. (2018): Grassland ecosystem responses to climate change and human activities within the Three-River Headwaters region of China. Scientific Reports 8: 9079. 
[19] Harris, R. B. (2010): Rangeland degradation on the Qinghai-Tibetan Plateau: a review of the evidence of its magnitude and causes. - Journal of Arid Environments 74: 1-12.

[20] He, L., Li, A., Yin, G., Nan, X., Bian, J. (2019): Retrieval of grassland aboveground biomass through inversion of the PROSAIL model with MODIS imagery. - Remote Sensing 11(13): 1597.

[21] Heute, A. R. (1988): A soil-adjusted vegetation index (SAVI). - Remote Sensing of Environment 25: 53-70.

[22] Houghton, R., Skole, D., Nobre, C. A., Hackler, J., Lawrence, K., Chomentowski, W. H. (2000): Annual fluxes of carbon from deforestation and regrowth in the Brazilian Amazon. - Nature 403: 301-304.

[23] Hsu, J. S., Powell, J., Adler, P. B. (2012): Sensitivity of mean annual primary production to precipitation. - Global Change Biology 18(7): 2246-2255.

[24] Huete, A., Justice, C., Liu, H. (1994): Development of vegetation and soil indices for MODIS-EOS. - Remote Sensing of Environment 49(3): 224-234.

[25] Ji, Q., Robeto, Q., Calos, L. (2008): Dry matter availability assessment in Tibetan grasslands using ground-level remotely-sensed data. - Acta Agrestia Sinica 16(1): 34-38.

[26] Jia, W. X., Liu, M., Yang, Y. H., He, H. L., Zhu, X. D., Yang, F., Yin, C., Xiang, W. N. (2016): Estimation and uncertainty analyses of grassland biomass in Northern China: comparison of multiple remote sensing data sources and modeling approaches. Ecological Indicators 60: 1031-1040.

[27] Jin, Y., Yang, X., Qiu, J., Li, J., Gao, T., Wu, Q., Zhao, F., Ma, H., Yu, H., Xu, B. (2014): Remote sensing-based biomass estimation and its spatio-temporal variations in temperate grassland, Northern China. - Remote Sensing 6(2): 1496-1513.

[28] Jobbagy, E. G., Sala, O. E. (2000): Controls of grass and shrub aboveground production in the Patagonian steppe. - Ecological Applications 10(2): 541-549.

[29] John, R., Chen, J., Giannico, V., Park, H., Xiao, J., Shirkey, G., Ouyang, Z., Shao, C., Lafortezza, R., Qi, J. (2018): Grassland canopy cover and aboveground biomass in Mongolia and Inner Mongolia: spatiotemporal estimates and controlling factors. Remote Sensing of Environment 213: 34-48.

[30] Lauenroth, W. K., Hunt, H. W., Swift, D. M., Singh, J. S. (1986): Estimating aboveground net primary production in grasslands-A simulation approach. - Ecological Modelling 33: 297-314.

[31] Liang, T., Yang, S., Feng, Q., Liu, B., Zhang, R., Huang, X., Xie, H. (2016): Multi-factor modeling of above-ground biomass in alpine grassland: A case study in the Three-River Headwaters Region, China. - Remote Sensing of Environment 186: 164-172.

[32] Liu, S., Zhou, L., Qiu, C. (1999): Grassland Degradation and Desertification in Naqu Prefecture of Tibet. - Lhasa: Tibet People's Press.

[33] Liu, S., Su, X., Dong, S., Cheng, F., Zhao, H., Wu, X., Zhang, X., Li, J. (2015): Modeling aboveground biomass of an alpine desert grassland with SPOT-VGT NDVI. - GIScience and Remote Sensing 52(6): 680-699.

[34] Liu, S., Cheng, F., Dong, S., Zhao, H., Hou, X., Wu, X. (2017): Spatiotemporal dynamics of grassland aboveground biomass on the Qinghai-Tibet Plateau based on validated MODIS NDVI. - Scientific Reports 7: 4182.

[35] Liu, Y. B., Xiao, J. F., Ju, W. M., Zhu, G. L., Wu, X. C., Fan, W. L., Li, D. Q., Zhou, Y. L. (2018): Satellite-derived LAI products exhibit large discrepancies and can lead to substantial uncertainty in simulated carbon and water fluxes. - Remote Sensing of Environment 206: 174-188.

[36] Lu, D. (2006): The potential and challenge of remote sensing-based biomass estimation. International Journal of Remote sensing 27(7): 1297-1328.

[37] Ma, W. H., Fang, J. Y., Yang, Y. H., Mohammat, A. (2010): Biomass carbon stocks and their changes in northern China's grasslands during 1982-2006. - Science in China series 53: 841-850. 
[38] Meng, B., Ge, J., Liang, T., Yang, S., Gao, J., Feng, Q., Cui, X., Huang, X., Xie, H. (2017): Evaluation of remote sensing inversion error for the above-ground biomass of alpine meadow grassland based on multi-source satellite data. - Remote Sensing 9(4): 372.

[39] Meng, B., Gao, J., Liang, T., Cui, X., Ge, J., Yin, J., Feng, Q., Xie, H. (2018): Modeling of alpine grassland cover based on unmanned aerial vehicle technology and multi-factor methods: a case study in the east of Tibetan Plateau, China. - Remote Sensing 10(2): 320.

[40] Ministry of Agriculture of China. (1996): Grassland Resources in China. - Beijing: Chinese Sciences and Technology Press.

[41] Nakchu Bureau of Animal Husbandry. (1992): Land Resources in Nakchu Prefecture of Tibet. - Chinese Agricultural Sciences and Technology.

[42] Ni, J. (2011): Impacts of climate change on Chinese ecosystems: key vulnerable regions and potential thresholds. - Regional Environmental Change 11: 49-64.

[43] North, P. R. J. (2002): Estimation of $f_{\mathrm{APAR}}$, LAI, and vegetation fractional cover from ATSR-2 imagery. - Remote Sensing of Environment 80(1): 114-121.

[44] Piao, S. L., Fang, J. Y., Ciais, P., Peylin, P., Huang, Y., Sitch, S., Wang, T. (2009): The carbon balance of terrestrial ecosystems in China. - Nature 458: 1009-1014.

[45] Salomonson, V. V., Appel, I. (2004): Estimating fractional snow cover from MODIS using the normalized difference snow index. - Remote Sensing of Environment 89(3): 351-360.

[46] Segoli, M., Ungar, E. D., Shachak, M. (2008): Shrubs enhance resilience of a semi-arid ecosystem by engineering and regrowth. - Ecohydrology 1(4): 330-339.

[47] Shen, M., Tang, Y., Klein, J. A., Zhang, P., Gu, S., Shimono, A., Chen, J. (2008): Estimation of aboveground biomass using in situ hyperspectral measurements in five major grassland ecosystems on the Tibetan Plateau. - Journal of Plant Ecology 1(4): 247257.

[48] Shen, M., Zhang, G., Cong, N., Wang, S., Kong, W., Piao, S. (2014): Increasing altitudinal gradient of spring vegetation phenology during the last decade on the QinghaiTibetan Plateau. - Agricultural and Forest Meteorology 189: 71-80.

[49] Tibet Land Management Bureau and Tibet Animal Husbandry Bureau. (1994): Grassland Resources in Tibet Autonomous Region. - Beijing: Science Press.

[50] Tsalyuk, M., Kelly, M., Koy, K., Getz, W. M., Butterfield, H. S. (2015): Monitoring the impact of grazing on rangeland conservation easements using MODIS vegetation indices. - Rangeland Ecology \& Management 68(2): 173-185.

[51] Wang, G. X., Li, Y. S., Wang, Y. B. (2007): Typical alpine wetland system changes on the Qinghai-Tibet Plateau in recent 40 years. - Acta Geographica Sinica 62(5): 481-491.

[52] Wang, J., Zhang, X., Chen, B., Shi, P. (2013): Causes and restoration of degraded alpine grassland in northern Tibet. - Journal of Resources and Ecology 4(1): 43-49.

[53] Wang, C., Guo, H., Zhang, L., Liu, S., Qiu, Y., Sun, Z. (2015): Assessing phenological change and climatic control of alpine grasslands in the Tibetan Plateau with MODIS time series. - International Journal of Biometeorology 59(1): 11-23.

[54] Wang, J., Xiao, X., Qin, Y., Doughty, R. B., Dong, J., Zou, Z. (2018): Characterizing the encroachment of juniper forests into sub-humid and semi-arid prairies from 1984 to 2010 using PALSAR and Landsat data. - Remote Sensing of Environment 205: 166-179.

[55] Wang, J., Xiao, X., Bajgain, R., Starks, P., Steiner, J., Doughty, R. B., Chang, Q. (2019): Estimating leaf area index and aboveground biomass of grazing pastures using Sentinel-1, Sentinel-2 and Landsat images. - ISPRS Journal of Photogrammetry and Remote Sensing 154: 189-201.

[56] Yan, F., Wu, B., Wang, Y. (2015): Estimating spatiotemporal patterns of aboveground biomass using Landsat TM and MODIS images in the Mu Us Sandy Land, China. Agricultural and Forest Meteorology 200: 119-128.

[57] Yang, Y. H., Fang, J. Y., Pan, Y. D., Ji, C. J. (2009): Aboveground biomass in Tibetan grasslands. - Journal of Arid Environments 73: 91-95. 
[58] Yang, S. X., Feng, Q. S., Liang, T. G., Liu, B. K., Zhang, W. J., Xie, H. J. (2018): Modeling grassland above-ground biomass based on artificial neural network and remote sensing in the Three-River Headwaters Region. - Remote Sensing of Environment 204: 448-455.

[59] Yuan, X., Li, L., Tian, X., Luo, G., Chen, X. (2016): Estimation of above-ground biomass using MODIS satellite imagery of multiple land-cover types in China. - Remote Sensing Letters 7(12): 1141-1149.

[60] Zhang, G., Zhang, Y., Dong, J., Xiao, X. (2013): Green-up dates in the Tibetan plateau have continuously advanced from 1982 to 2011. - PNAS 110(11): 4309-4314.

[61] Zhang, C. Y., Denka, S., Cooper, H., Mishra, D. R. (2018): Quantification of sawgrass marsh aboveground biomass in the coastal Everglades using object-based ensemble analysis and Landsat data. - Remote Sensing of Environment 204: 366-379.

[62] Zhao, F., Xu, B., Yang, X., Jin, Y., Li, J., Xia, L., Chen, S., Ma, H. (2014): Remote sensing estimates of grassland aboveground biomass based on MODIS net primary productivity (NPP): A case study in the Xilingol grassland of Northern China. - Remote Sensing 6(6): 5368-5386.

[63] Zheng, D., Rademacher, J., Chen, J., Crow, T., Bresee, M., Le Moine, J., Ryu, S-R. (2004): Estimating aboveground biomass using Landsat 7 ETM+ data across a managed landscape in northern Wisconsin, USA. - Remote Sensing of Environment 93(3): 402411. 